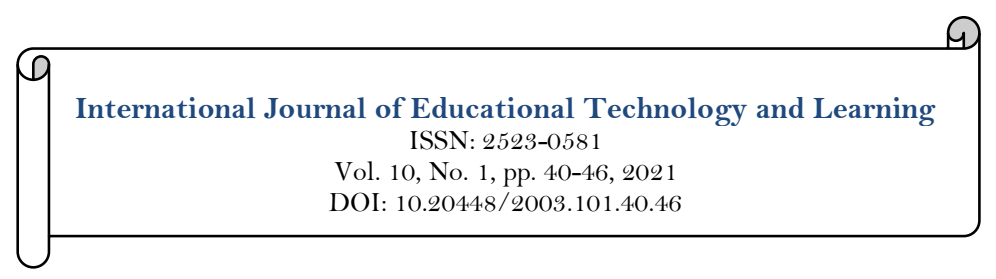

\title{
Strategies for Information Design and Processing of Multimedia Instructional Software - Based on Richard E. Mayer's Multimedia Instructional Design Principles
}

\author{
Shan $\mathbf{G e}^{1}$ \\ Xiaoyun Lai ${ }^{2 *}$ \\ 'Beijing Institute of Petrochemical Technology, Beijing, China. \\ ¿School of Journalism and Communication, Gannan Normal University, Jiangxi Province, China. \\ Email:geshan@bipt.edu.cn
}

\section{Abstract}

Multimedia instruction means presenting words and pictures that are intended to promote learning. Since there are severe limits on the amount of information processed in human working memory, multimedia instructional messages should be so designed as to guide appropriate cognitive processing during learning without overloading the learner's cognitive system. To maximize learners' cognitive processing of information, the information design and processing of multimedia instructional software must be consistent with the multimedia learning theory and mechanism so as to promote meaningful learning. It is found that the instructional methods like visualizing multimedia information, managing essential processing, reducing extraneous processing and fostering generative processing, devised in accordance with Mayer's multimedia learning principles, can significantly improve the effect of information representation and transmission, which, to a great extent, helps curb teachers' tendency to neglect learners' cognitive mechanism while processing the information of multimedia instructional software, and thus provides insight into multimedia instruction as well as the design of multimedia instructional software.

Keywords:

Dual coding

Cognitive load

3-Fold model

Information processing.

Licensed:

This work is licensed under a

Creative Commons Attribution 4.0

License.

Publisher:

Scientific Publishing Institute

Received: 28 December 2020

Revised: 15 January 2021

Accepted: 26 January 2021

Published: 12 February 2021

( Corresponding Author)

Funding: The authors received no funding for this study.

Competing Interests: The authors declare that they have no competing interests.

\section{Introduction}

With the development of educational informatization in China, multimedia instructional software has become an important information carrier of teaching and learning. However, most of the current teaching software fails to give due attention to the design of instructional messages in line with psychological working mechanism of learners. The purpose of multimedia instructional software is to improve the effect of teaching and learning. Poor design of instructional software will impair learning effect. Richard Mayer believes that the design of multimedia instructional messages should be compatible with how people learn. "A fundamental hypothesis underlying research on multimedia learning is that multimedia instructional messages that are designed in light of how the human mind works are more likely to lead to meaningful learning than those that are not so designed"(Mayer, 2014).

Richard E. Mayer is an American educational psychologist who has made significant contributions to theories of cognition and learning, especially multimedia learning theory. He and his colleagues designed more than 100 experiments to test the influence of different multimedia information representation modes on learning effect, and constructed multimedia instruction principles by integrating teaching and multimedia. The process of multimedia learning involves two important cognitive mechanisms: one is the dual channel 
mechanism which assumes that "humans possess separate information processing channels for visually/spatially represented material and auditorily/verbally represented material," (Mayer, 2014) and the learning effect of dual channel is better than that of single channel (Mayer, 2002). Starting from this assumption, Mayer put forward the cognitive theory of multimedia learning, focusing on the dual coding of multimedia messages. The second is the limited capacity mechanism originating from cognitive load theory, on the basis of which, Mayer constructed a 3-fold model of cognitive load and proposed principles for reducing extraneous cognitive load and increasing germane cognitive load. Mayer's multimedia learning theory is easy to apply and has practical significance for the information processing of multimedia instructional software.

\section{Dual Coding and Information Visualization Methods in Multimedia Instructional Software}

According to Mayer, multimedia presents both words and pictures and "multimedia learning occurs when people build mental representations from words (such as spoken text or printed text) and pictures (such as illustrations, photos, animation, or video)" (Mayer, 2014). He proposed a cognitive model of multimedia learning on the basis of Paivio's "dual coding" theory which states that human beings have two sets of independent but interrelated information processing systems: one is verbal system used to process verbal information, the other is image system used to process visual information (Paivio, 1986). Paivio found after many experiments that learners can recall more with both words and pictures than with only words, and the image system is generally more impressive and advantageous than the verbal system (Clark \& Paivio, 1991). Mayer analyzed dual coding with the information processing mode and proposed the cognitive theory of multimedia learning as shown in Figure 1 (Mayer, 2014).

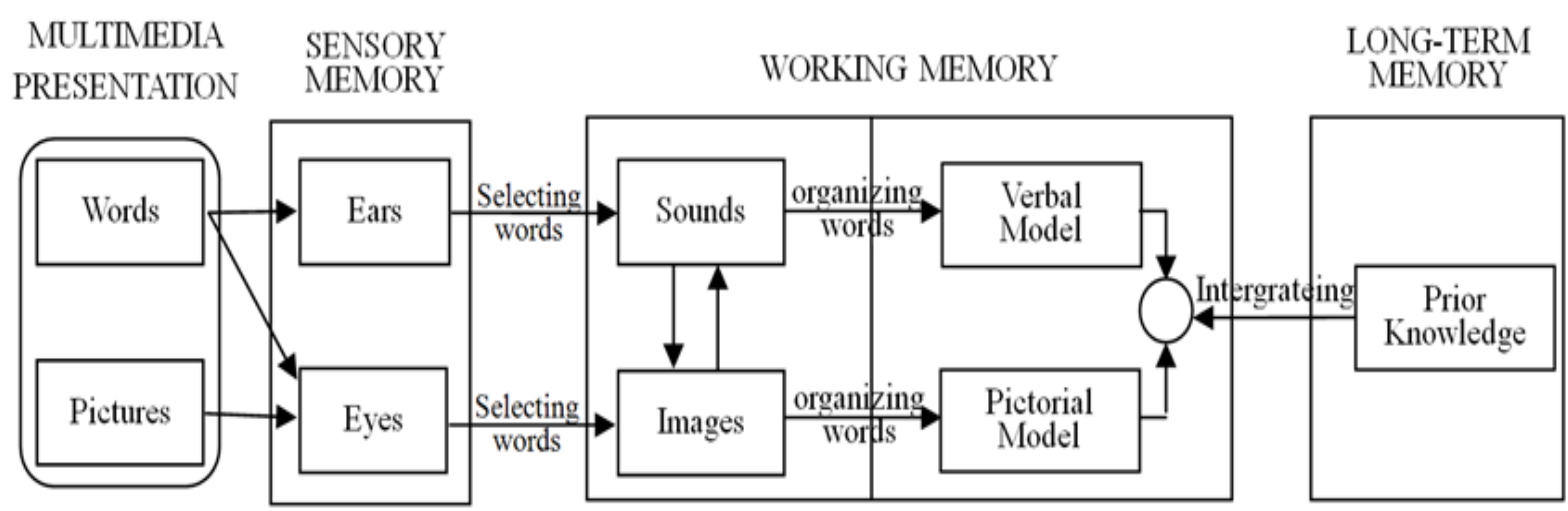

Figure-1. Mayer's cognitive theory of multimedia learning (Mayer, 2014).

"Words" in Figure 1 includes not only written words, but also spoken words, that is, the teacher's spoken language and the dubbing of multimedia instructional software. "Pictures" refers to both static and dynamic images. Static images include illustrations, graphics, maps, strokes, pictures and images produced by various drawing software. Dynamic images include animation, video clips, etc.

When vision and hearing act on human's sensory organs at the same time, visual information is encoded by non-verbal system, whereas verbal information is encoded by verbal system. Information in visual memory area also leaves corresponding marks in verbal memory area.

Since information is stored in two memory areas at the same time and encoded in two ways, it provides two kinds of clues for recall. Therefore, the information processing of "words + pictures" is beneficial not only to the understanding of messages, but also to the memorizing of messages. When the information of instructional software is processed, the visual pictures can be used to improve the perceptibility of teaching materials, which is convenient for learners to understand and remember.

To visualize teaching information, different methods should be adopted after analyzing the characteristics of the knowledge presented in the multimedia instructional software. Knowledge is generally divided into declarative knowledge, procedural knowledge and strategic knowledge. Declarative knowledge, also known as depictive knowledge, is mainly used to explain the nature, characteristics and state of things, and to distinguish things, such as symbols, facts and general knowledge.

Declarative knowledge can be represented by propositional network or images, objects, etc. Procedural knowledge is skill knowledge represented by action, which focuses on imitation and operation. Programmed and automated, procedural knowledge can be represented by flow charts, animations, videos and so on. Strategic knowledge refers to the ability to solve problems in complex situations and to construct new knowledge by transferring the acquired knowledge to the actual situation, which can be represented by creating relevant problem situations with physical objects and animations.

In the design of instructional software, the processing of knowledge should be coupled with teachers' explanation or video dubbing to achieve dual coding, which can help students better understand the message. Table 1 illustrates how to visualize the knowledge of place setting in the course of Western Etiquette. 
Table-1. Visualization of different categories of knowledge.

\begin{tabular}{|c|c|c|c|c|c|}
\hline $\begin{array}{l}\text { Categories } \\
\text { of } \\
\text { Knowledge }\end{array}$ & $\begin{array}{l}\text { Description of } \\
\text { Knowledge }\end{array}$ & $\begin{array}{l}\text { Cognitive } \\
\text { Skills }\end{array}$ & $\begin{array}{l}\text { Visualizatio } \\
\text { n Methods }\end{array}$ & $\begin{array}{l}\text { Multimedia } \\
\text { Instruction } \\
\text { Software } \\
\end{array}$ & $\begin{array}{l}\text { Tools and } \\
\text { Representation } \\
\text { Methods }\end{array}$ \\
\hline $\begin{array}{l}\text { Declarative } \\
\text { Knowledge }\end{array}$ & $\begin{array}{lr}\text { symbols, facts } \\
\text { and general } \\
\text { knowledge }\end{array}$ & $\begin{array}{l}\text { Tell different } \\
\text { pieces of } \\
\text { tableware for } \\
\text { a formal } \\
\text { dinner }\end{array}$ & $\begin{array}{ll}\text { Objects } & \text { or } \\
\text { pictures } & \end{array}$ & $\begin{array}{l}\text { Demonstratio } \\
\text { n courseware }\end{array}$ & Photoshop \\
\hline $\begin{array}{l}\text { Procedural } \\
\text { Knowledge }\end{array}$ & $\begin{array}{l}\text { skills, } \\
\text { procedures, } \\
\text { knowledge of } \\
\text { programming } \\
\text { and automation }\end{array}$ & $\begin{array}{l}\text { Explain } \\
\text { procedures to } \\
\text { set the table } \\
\text { for a formal } \\
\text { dinner }\end{array}$ & $\begin{array}{l}\text { flow charts, } \\
\text { animations, } \\
\text { video clips }\end{array}$ & $\begin{array}{l}\text { demonstration } \\
\text { and practicing } \\
\text { software }\end{array}$ & $\begin{array}{l}\text { mind mapping tools } \\
\text { for making flow } \\
\text { charts; video editing } \\
\text { software like flash } \\
\text { and Movie Maker to } \\
\text { produce animations }\end{array}$ \\
\hline $\begin{array}{l}\text { Strategic } \\
\text { Knowledge }\end{array}$ & $\begin{array}{l}\text { flexible } \\
\text { application of } \\
\text { knowledge to } \\
\text { solve problems }\end{array}$ & $\begin{array}{l}\text { set the table } \\
\text { for a formal } \\
\text { dinner }\end{array}$ & $\begin{array}{l}\text { pictures, } \\
\text { objects and } \\
\text { animations }\end{array}$ & $\begin{array}{l}\text { practicing and } \\
\text { gaming } \\
\text { software }\end{array}$ & $\begin{array}{lr}\text { create } & \text { problem } \\
\text { situations by using } \\
\text { Flash or } 3 \mathrm{ds} \text { Max } \\
\text { for students to } \\
\text { practice }\end{array}$ \\
\hline
\end{tabular}

Through these visualization methods, the abstract knowledge is made concrete and thus more perceptible. With the stimulation of both words and pictures, dual coding can help students better acquire knowledge.

In the processing of instructional software information, most visual elements are not ready-made and need to be edited according to the nature and characteristics of teaching information. Different types of visual symbols can be produced by corresponding visualization tools. Figure 2 lists the visualization tools for making graphics, videos and animations. Teachers may choose what they like to serve their purposes.

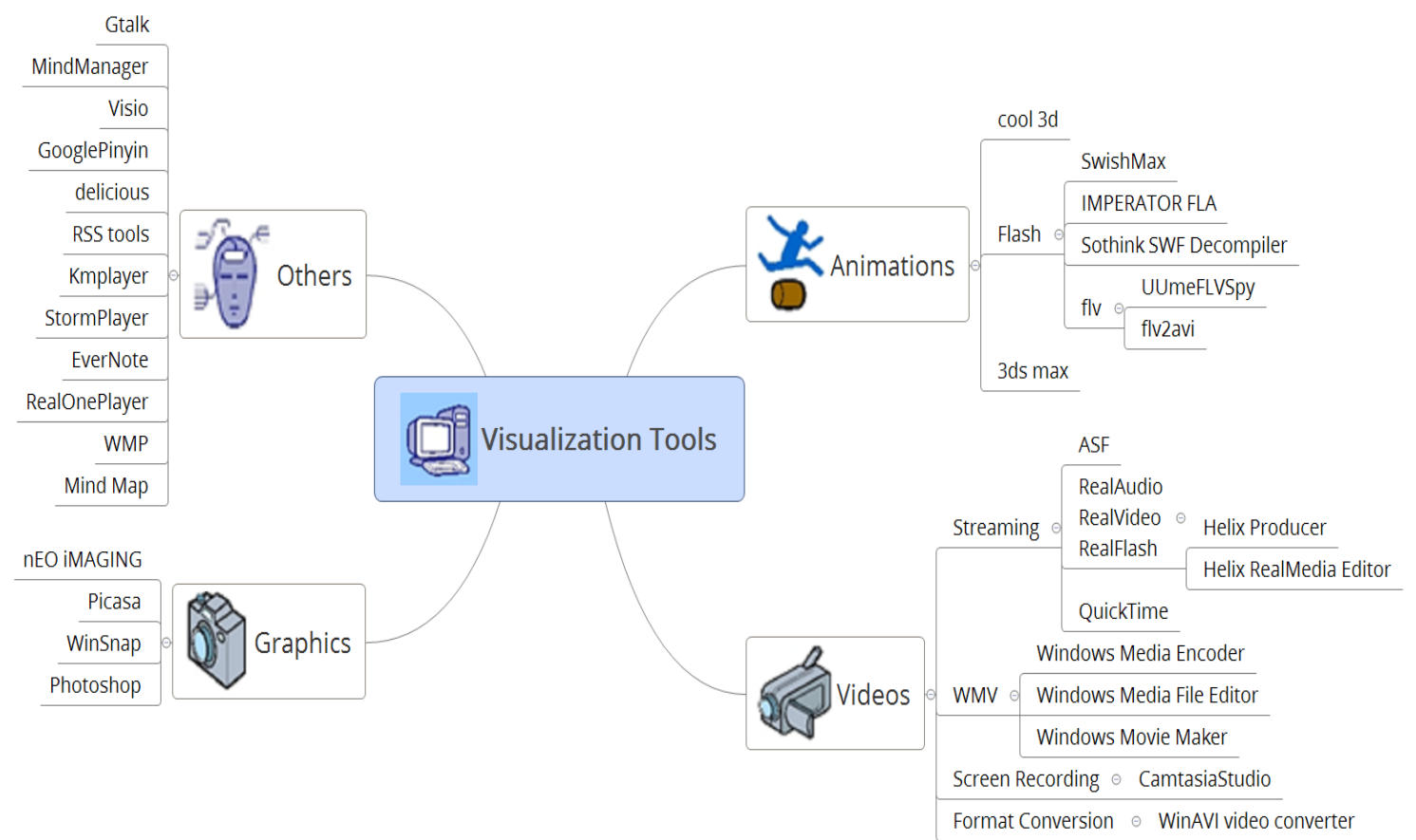

Figure-2. Visualization tools for different visual elements.

\section{Cognitive Load Theory of Multimedia Learning and Information Processing Strategies of} Multimedia Instructional Software

3.1. Cognitive Load Theory of Mayer's Multimedia Learning

Cognitive load refers to the load imposed on working memory by information being presented (Sweller, Ayres, \& Kalyuga, 2011). In the process of learning, the learner's cognitive activities need to consume cognitive resources. When the presented learning materials exceed the total amount of the learner's working memory, the learner's cognitive system will be overloaded. Cognitive load can be categorized into intrinsic cognitive load, extraneous cognitive load and germane cognitive load. Intrinsic cognitive load is the load imposed by essential, interacting elements that must be processed simultaneously in working memory; 
extraneous cognitive load is the load imposed by nonessential, interacting elements that should be reduced by altering the instructional design; germane cognitive load refers to working memory resources devoted to dealing with intrinsic rather than extraneous cognitive load, which should be increased to facilitate learning (Paas \& Sweller, 2014). Teaching effect will be improved by the instructional design that reduces the extraneous cognitive load and enhances the germane cognitive load. As Yeung, Jin, and Sweller (1998) demonstrated, cognitive load is regarded as an important factor in the design of instructional activities. The effectiveness of instructional activities depends (or partly depends) on whether it can reduce unnecessary cognitive processing.

In order to improve the effect of multimedia learning, Mayer and Moreno introduced the cognitive load theory into multimedia learning and, after repeated experimental verification, formed the 3-fold model of cognitive processing which matches the three kinds of cognitive load, namely, essential cognitive processing, extraneous cognitive processing and generative cognitive processing. The mapping relationship is shown in Figure 3.

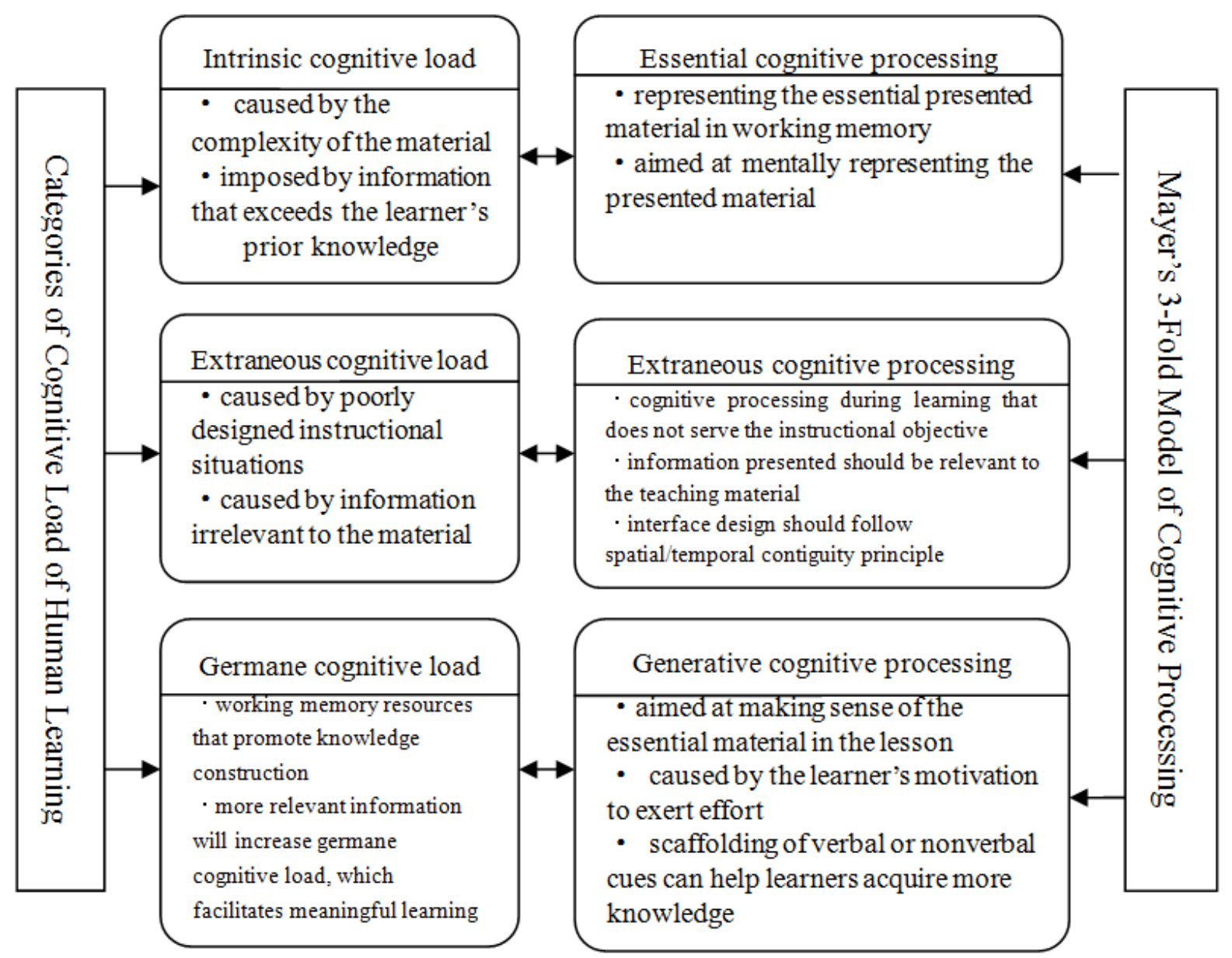

Figure-3. Mayer's 3-fold model of cognitive processing in relation to cognitive load of human learning (Mayer, 2014).

Based on cognitive load theory, Mayer's 3-fold model of cognitive processing can effectively reduce the extraneous cognitive load in human learning, increase the germane cognitive load, and thus optimize multimedia learning effect. Essential processing is analogous to intrinsic cognitive load in cognitive load theory, which is necessary for learners to understand the learning materials. The learner's acquisition depends on the complexity of the learning materials presented. Essential processing results in the construction of verbal and pictorial representations in working memory that correspond to the presented material. Extraneous processing, analogous to extraneous cognitive load in cognitive load theory, is caused by poor instructional design. If the words or pictures presented in multimedia messages are not relevant to the teaching content, such as fancy decorations, or if the words and pictures are not laid out in accordance with the spatial contiguity and temporal contiguity principle, it will unnecessarily increase the number of interacting elements that learners must process. Extraneous cognitive load should be reduced by altering the inappropriate instructional design which does not lead to knowledge acquisition. Generative processing, analogous to germane cognitive load in cognitive load theory, is the deep cognitive processing of learners. Adding relevant verbal or non-verbal cues in multimedia learning materials can help learners engage in generative processing. 
Mayer developed a series of principles of multimedia learning to reduce extraneous processing to allow more available cognitive capacity for essential and generative processing. For example, coherence principle, signaling principle, redundancy principle, spatial contiguity principle, temporal contiguity principle, and segmenting principle are proposed to minimize extraneous processing; pre-training principle, modality principle, and multimedia principle are promoted to manage essential processing; personalization principle, voice principle, embodiment principle, guided discovery principle, self-explanation principle, and drawing principle are raised to foster generative processing (Mayer, 2014). All these principles lay down guidelines for the information processing of multimedia instructional software.

\subsection{Information Processing Strategies of Multimedia Instructional Software}

Mayer's 3-fold model of cognitive processing and representative principles provide insight into the information presentation and interface design of multimedia instructional software as shown in Table 2.

Table-2. Strategies for multimedia instructional design in light of Mayer's instructional principles (Mayer, 2014).

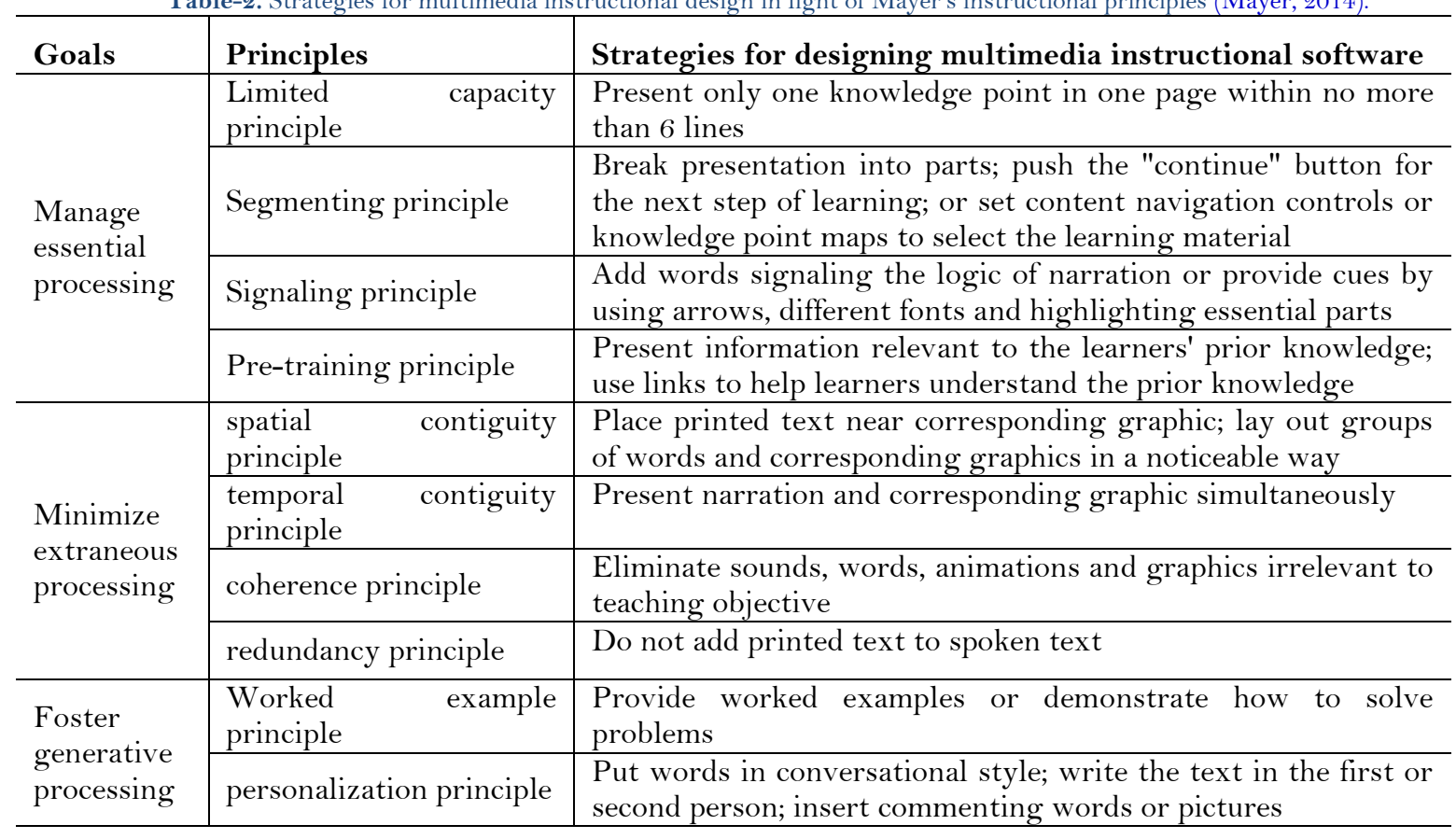

\subsubsection{Managing Essential Cognitive Processing}

The strategy of managing essential cognitive processing in multimedia instructional design concerns the amount of information presented in one page and its layout. According to the " $7 \pm 2$ " chunk theory raised by cognitive psychologist Miller (1956) the capacity of short-term memory per unit time is limited, and people can only remember five to nine unconnected units of perceived information. Therefore, in the design of multimedia instructional software, it is recommended to present 5 to 7 pieces of information on one page, and the information presented should be highly condensed and closely related so as to help students better process the information.

In the structural design of teaching information, segmenting principle and signaling principle can be adopted to improve the layout of complex information on one page, for example, setting knowledge maps and navigation tools to allow learners more time to process the information, or providing signaling cues to help the cognitive processing of teaching information. The knowledge navigation shown in Figure 4 illustrates the steps of computer assembly. A click on each step can bring the learner to the corresponding page where the learner can find relevant content by clicking the "content" button. Mayer pointed out that learners' cognitive processing can be much improved by highlighting essential parts or adding words which signal the logic of narration, such as "therefore" and "as a result" to indicate cause and effect, "first" and "second" to suggest sequence, and "in short" to signal conclusion. 


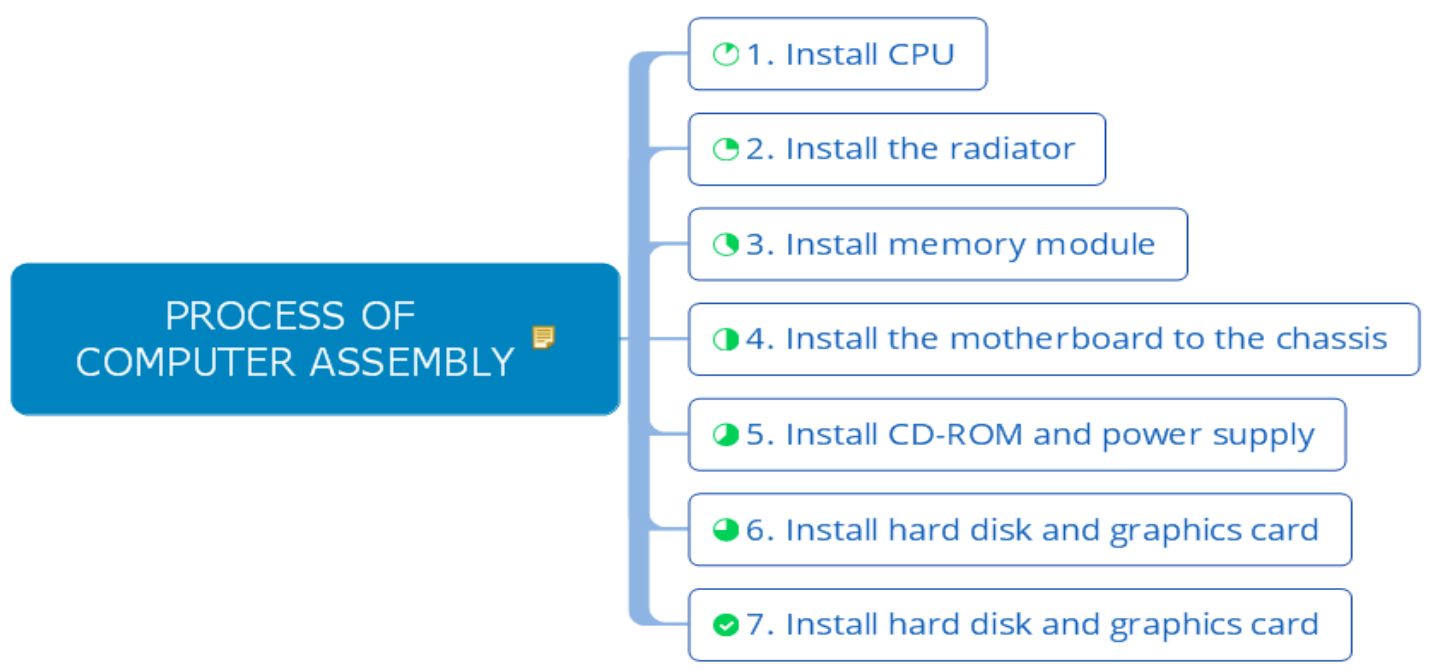

Figure-4. Navigation diagram of computer assembly.

When multimedia instructional messages go beyond the scope of learners' prior knowledge, hyperlinks must be provided for learners to relate the current knowledge to their prior knowledge. It is worth noting that the information presented must be near the learner's "zone of proximal development".

\subsubsection{Minimizing Extraneous Cognitive Processing}

The strategy of minimizing extraneous cognitive processing can be applied to information layout design, interface design and control of information processing channel.

For better information layout, Mayer recommended spatial contiguity principle and temporal contiguity principle. When multimedia instructional messages include both words and pictures, embedding words in the picture is better than placing them below the picture since the former mode better helps learners to generate corresponding mental representation and thus incorporate the two sources of information into working memory for cognitive coding. As to the time of information presentation, Mayer advocated temporal contiguity principle, saying "students learn better when corresponding words and pictures are presented simultaneously rather than successively" (Mayer, 2014). For example, in an animation, explanatory spoken text should go together with the picture so that learners can build connections between corresponding portions of the pictorial and verbal models in visual and verbal working memory, which helps to integrate word-based and picture-based representations.

As to interface design, coherence principle should be observed to eliminate words, animations, pictures and videos irrelevant to the teaching material. Many teachers like to include some interesting animations or pictures in the courseware. The irrelevant information will overload learners' cognitive capacity and increase extraneous processing, which will decrease essential and generative processing. In general, $70 \%$ of the interface of multimedia instructional software is used for information presentation, and $30 \%$ for beautification. Simple lines or processed pictures are preferred to animations for beautification, and no more than three colors should be used for large areas in one page.

When the information presented is complicated and has to be kept in multimedia software, signaling or cueing principle should be applied to reduce extraneous cognitive load for learners. According to Mayer, people learn more deeply from a multimedia message when cues are added that guide attention to the relevant elements of the material or highlight the organization of the essential material (Mayer, 2014). Cues come in many forms. Text-based cues can consist of topic shifts, outlines or headings, and signaling the spoken text. Picture-based cues can include arrows, colors, spotlight, and gestures (Wang, Duan, \& Zhou, 2013). Mautone and Mayer (2001) used the cues like arrows, color, and summary icons in an animation on how airplanes fly and found, after comparing the cued and uncued animation conditions, that cueing is beneficial to knowledge transfer. It is revealed that signaling not only may prevent extraneous load by preventing processing of less relevant information, but may simultaneously foster germane load by facilitating the organization or integration of essential material.

It is assumed that humans possess separate information processing channels for visually represented material and auditorily represented material. Since humans are limited in the amount of information that can be processed in each channel at one time, redundancy principle should be applied to ensure active processing. According to Mayer, material representation modes in multimedia instructional design should be limited to animations and narration, that is, printed text should not be added to spoken text. It shows that the representation mode of "animation + narration" of multimedia message beats that of "animation + narration + on-screen text" in promoting learners' cognitive processing of essential materials. Generally speaking, multimedia presentation of teaching content can meet the needs of students with different learning styles. 
Learners can choose their familiar ways to process information presented in the multimedia software. However, Mayer's multimedia learning theory holds that animations and on-screen text belong to the same visual channel. When two forms of information are presented simultaneously, learners find it hard to process the information of the same channel at one time due to humans' limited capacity of working memory. Therefore, redundancy principle should be observed in multimedia instructional design.

\subsubsection{Fostering Generative Cognitive Processing}

Generative cognitive processing is a kind of structuralist instructional mode, which is helpful to learners' deep cognitive processing. In multimedia instructional design, learners' potential cognitive ability should be fully stimulated, so as to promote learners' interest in learning and facilitate their deep learning of the material. Worked example principle and personalization principle can be adopted to foster generative cognitive processing in multimedia instructional design.

Worked example principle refers to providing worked examples which display detailed procedures for solving problems in the design of multimedia instructional software. The provided examples should clearly show the logical relationship between procedures, from which learners can summarize the implicit abstract knowledge to acquire skills for solving problems and achieve knowledge transfer. Using multiple worked examples benefits knowledge construction, especially when it comes to complex concepts and complex problem-solving skills.

Personalization principle refers to the integration of social cues into multimedia messages, such as conversational style, the first or second person, and the appropriate insertion of some commenting words or images, especially encouraging words or pictures, to activate learners' social response. It promotes active cognitive processing which leads to meaningful learning. According to Constructivism Learning Theory, situation and learning community lie at the core of learning and community participation helps learners construct knowledge. On the basis of constructivist research, Mayer put forward the social agent theory of multimedia learning. Adding social cues in multimedia instructional software will give learners a sense of belonging which engages learners in active cognitive processing, such as selecting, organizing, and integrating.

\section{Conclusion}

Multimedia instructional software serves different learning purposes, for example, demonstration, autonomous learning, and practice, etc. No matter what purposes the software serves, it must conform to human cognitive mechanism and reduce cognitive load in order to promote meaningful learning. The information processing strategies of multimedia instructional software raised on the basis of Mayer's multimedia instructional design principles may help teachers to design high-quality courseware in line with students' cognitive characteristics, and thus facilitate meaningful learning outcomes in multimedia environments.

\section{References}

Clark, J. M., \& Paivio, A. (1991). Dual coding theory and education. Educational Psychology Revierw, 3(3), 149-170.

Mautone, P. D., \& Mayer, R. E. (2001). Signaling as a cognitive guide in multimedia learning. Journal of Educational Psychology, 93(1), 377-389.

Mayer, R. E. (2002). Cognitive theory and the design of multimedia instruction: An example of the two-way street between cognition and instruction. New Directions for Teaching and Learning, 89(spring), 55-71.

Mayer, R. E. (2014). The cambridge handbook of multimedia learning-second edition. New York: Cambridge University Press.

Miller, G. A. (1956). The magical number seven, plus or minus two: Some limits on our capacity for processing information. The Psychology Review, 63(2), 81-97.

Paas, F., \& Sweller, J. (2014). Implications of cognitive load theory for multimedia learning, In R. E. Mayer(Ed), The Cambridge Handbook of Multimedia Learning (Second Edition (pp. 40-54). New York: Cambridge University Press.

Paivio, A. (1986). Mental representations: A dual coding approach. Oxford, England: Oxford University Press.

Sweller, J., Ayres, P., \& Kalyuga, S. (2011). Cognitive load theory. New York.: Springer.

Wang, F., Duan, Z. H., \& Zhou, Z. K. (2013). Attention guidance in multimedia learning: The role of cueing. Advances in Psychological Science, 21(8), 1430-1440.Available at: https://doi.org/10.3724/sp.j.1042.2013.01430.

Yeung, A. S., Jin, P., \& Sweller, J. (1998). Cognitive load and learner expertise: Split-attention and redundancy effects in reading with explanatory notes. Contemporary Educational Psychology, 23(1), 1-21.Available at: https://doi.org/10.1006/ceps.1997.0951. 